\title{
Polymorphisms in DSSP (rs36094464) and RUNX2 (rs566712) Genes Contribute to the Susceptibility of Dental Caries in Childhood
}

\author{
Los Polimorfismos en los Genes DSSP (rs36094464) y RUNX2 (rs566712) \\ Contribuyen a la Susceptibilidad de la Caries Dental en la Infancia
}

Jorge Sanhueza ${ }^{1,2}$; Luis Bustos ${ }^{3}$; Nelia Rodríguez ${ }^{1}$; Evelyn Borie-Echeverria ${ }^{4}$ \& Paulo Salinas $^{5}$

SANHUEZA, J.; BUSTOS, L.; RODRÍGUEZ, N.; BORIE-ECHEVERRIA, E. \& SALINAS, P. Polymorphisms in DSSP (rs36094464) and RUNX2 (rs566712) genes contribute to the susceptibility of dental caries in childhood. Int. J. Morphol., 39(3):802-808, 2021.

SUMMARY: Dental caries corresponds to an ecological and non-contagious, dynamic and chronic disease of multifactorial origin; currently there is evidence of how genetic factors could be included as predisposing agents to suffer it, however this evidence is diverse and incipient. a cross-sectional study was p erformed to investigate the possible associations of DSPP (rs36094464), RUNX2 (rs566712) and KLK4 (rs198968) polymorphisms in early childhood caries. Saliva samples of children (2-11years old) were collected and genotyped for DSPP (rs36094464), RUNX2 (rs566712) and KLK4 (rs198968) polymorphisms. Through the ceft index their caries history was determined and the gene variants were students through molecular biology techniques. polymorphisms of the DSSP (rs36094464) and RUNX2 (rs566712) are associated and contribute to the susceptibility of dental caries disease in early childhood, as they are related to their history of caries. KLK4 (rs198968) polymorphisms are not associated. In conclusions, the studied polymorphisms on DSSP and RUNX2 genes are associated with changes in the tooth microarchitecture, favoring the appearance of microlesions that would contribute to dental caries disease susceptibility in early childhood. Also, no association was found for the studied polymorphism of the KLK4 gene with dental caries disease susceptibility.

\section{KEY WORDS: Caries; Childhood; Polymorphisms; DSPP; RUNX2}

\section{INTRODUCTION}

Dental caries corresponds to an ecological, not contagious, dynamic and chronic disease with a multifactorial origin, that occurs as a product of an alteration of the bacterial plaque adhered to the teeth (biofilm), either by changes in diet, lifestyle habits, oral hygiene, saliva or even changes in the immune system. Dental caries is one of the most prevalent chronic diseases in children, being five times more frequent than asthma and fourteen times more frequent than chronic bronchitis. Therefore, it is one of the most important diseases of dentistry and a high important challenge in child public health. The World Health Organization has estimated that between 60 and $90 \%$ of the children globally have carious lesions with evident cavitation (World Health Organization, 2019). The prevalence of early childhood caries differs according to the studied group due to its multifactorial nature, reaching up to $85 \%$ (Anil \& Anad, 2017).
The severity of the dental caries problem can be estimated through the ceft index (Peter, 2006), which measures the present and past experience of caries, where "c" indicates decayed teeth (evidence of dental caries, cavitation, including filled teeth with recurrent caries), "e" extracted teeth and decayed teeth indicated for extraction due to caries, and "f" filled (restored teeth without recurrent caries).

The pathophysiological process of dental caries is characterized by loss of density in the hard tissues of the tooth (enamel, dentin and root cement) as a consequence of demineralization caused by alterations of the dynamic balance of the tooth, its environment and microbiome (Philip et al., 2018). The oral microbiome is diverse and dynamic; however, it has been reported that Streptococcusmutans exhibits the highest association to dental caries (Colombo et al., 2017). It has been proposed that caries does not need

\footnotetext{
${ }^{1}$ School of Medicine, Faculty of Sciences, Universidad Mayor, Temuco, Chile.

${ }^{2}$ Laboratory of Applied Cellular and Molecular Biology, Universidad Mayor, Temuco, Chile.

${ }^{3}$ Department of Public Health and CIGES, Faculty of Medicine, Universidad de La Frontera, Temuco, Chile.

${ }^{4}$ School of Dentistry, Faculty of Sciences, Universidad Mayor, Temuco, Chile.

${ }^{5}$ Laboratory of Animal \& Experimental Morphology, Institute of Biology, Faculty of Sciences, Pontificia Universidad Católica de Valparaíso, Valparaíso, Chile.
} 
to be "cured" by eliminating the bacteria with a subsequent rehabilitation of the cavity, but must be treated by controlling the etiological factors6 (fermentable carbohydrates and bacterial biofilm). An imbalance in the biofilm can be caused by factors such as decreased salivary flow, diet and lifestyle changes, poor oral hygiene or a depressed immune system, overall turning it more cariogenic.

Even though the presence of biofilm and fermentable carbohydrates are the leading risk factors for the development of dental caries, currently there is evidence supporting that host genetic factors are implicated in the etiology of caries (Opal et al., 2015). A growing number of studies report a set of genes recently associated with this health problem, mainly focusing on three key points: i) genes involved in tooth enamel development, ii) genes involved in the tooth's immune response and iii) genes involved in diet diversity and carbohydrate metabolism (Bretz et al., 2003; Opal et al.).

Amelogenesis, or tooth enamel formation, has two stages: secretory and maturation. During the secretory stage, ameloblasts synthesize and secrete a limited amount of structural enamel extracellular matrix proteins: amelogenin, ameloblastin, and enamelin. During the maturation phase, the enamel layer reaches its maximum thickness, with the minerals deposit at this stage depending on the degradation of the extracellular matrix. This is composed by matrix structural proteins, which should be absent in the late stage of maturation. Degradation of such proteins is associated with the synthesis of two proteases: enamelysin (MMP20) and kallikrein 4 (KLK4), genetic variants of these proteases have been associated with amelogenesis imperfecta (Ozdemir et al., 2005). In addition, other studies affirm that polymorphisms of the KLK4 gene can increase enamel porosity and promote a reduction of the mineral that provides the biofilm adhesion (Lu et al., 2008; Opal et al.). Dentine sialophosphoprotein (DSPP) is another important protein in the process of enamel formation and gives rise to noncollagenous proteins dentine sialoprotein and dentine phosphoprotein (50\% non-collagen component), essential components of dentin extracellular matrix and the mineralization process. Mutations in the DSPP gene are associated with dentinogenesis imperfecta (DI) and dentine dysplasia (Maciejewska \& Chomik, 2012). The runt-related transcription factor-2 (RUNX2) regulates osteoblast differentiation, the cells responsible for secreting the compounds of the new bone matrix and for regulating its mineralization (Perinpanayagam et al., 2006). In order to achieve good mineralization, an adequate quantity and differentiation of odontoblasts are required. In addition, an extracellular matrix (aligned collagen, sialoproteins and phosphoproteins) in optimal conditions is needed to carry out processes of inorganic material apposition.
Recent studies continue to demonstrate that genetic variations in the host are associate with dental caries, these variations that may play a role in dental caries etiology as risk or protective factors (Schaffer et al., 2011; Wang et al., 2012; Shimizu et al., 2012, 2013; Vieira et al., 2014). These association studies include polymorphisms in genes that have an essential part in the tooth formation process, the composition of saliva, taste preferences and the mouth's immune system. However, they reflect an increased complexity of these associations by diverse genetic phenotypes associated with the study population (Opal et al.; Philip et al.; Kamel et al., 2018), which requires additional research, not only in the same populations but also to replicate and identify new genes in different ethnic groups (Opal et al.). Evidence regarding genetic association with caries disease in early childhood is scarce, and existing studies hypothesize that some genes are differentially expressed in primary enamel and that polymorphisms in these genes could lead to an increased susceptibility to dental caries (Piekoszewska-Zietek et al., 2017). Here, we hypothesized that the modifications of genes involved in amelogenesis would contribute to the development of caries. The aim of the present study was to evaluate if DSPP (rs36094464), RUNX2 (rs566712) and KLK4 (rs198968) polymorphisms are associated with caries in childhood.

\section{MATERIAL AND METHOD}

Ethics Statement. This study was conducted at the university dental clinic in Temuco, Chile with ethical approval from the Research Ethics Committee CE 296/2019 of Universidad Mayor. All procedures were performed conformed to the Declaration of Helsinki. Participants provided assent as well as adequate understanding and written consent from the parents. Written informed consent and assent were obtained from parents or responsible guardians, and subjects, respectively.

Study population and groups. In this cross-sectional study, Chilean pediatric patients $(n=125)$ with ages from 2 to 11 years who regularly attended comprehensive dental care were included. The inclusion criteria were: i) to have a clinical record with their general, medical and dental background, registered through the SMILE software, and ii) to present a primary temporary or mixed dentition. An oral examination was carried out to evaluate the child's history of caries by calculating the ceft (carious, extracted, filled, teeth) index. For the comparative analysis of variables, individuals were classified into two groups: ECC $(\leq 8$ years old, early childhood caries) and CC (> 8 years of age, caries in childhood). These groups were formed according to the 
recommendations of UNICEF and the Committee on the Rights of the Child, and to previous evidence. There is potential selection bias in this study, since the patients who participated in the study were recruited exclusively from the university dental clinic. These patients tend to have different characteristics from the general population, for example, they have a higher socio-economic level.

Samples collection, DNA extraction and polymorphic variants genotyping. During the oral examination process of each participant, a saliva sample was obtained from the buccal mucosa for genomic DNA extraction using forensic collection pallets (PureLink Pro 96 Genomic DNA Purification Kit, Thermo Fisher Scientifics $®)$. Genotypic variants were identified by PCR and PCR-RFLP techniques with subsequent allele discrimination by agarose gel electrophoresis.

Statistical analysis. A descriptive analysis including frequencies, percentages, and means \pm standard deviation (SD) is presented. Fisher's exact test was used for percentages comparison and for means the ANOVA test, Student's t-test and multiple Sheffé comparisons were used. The magnitude of the associations was estimated by calculating the odds ratio (OR) with a confidence interval (CI) of $95 \%$. Statistical significance for all of hypotheses tests was set at $p<0.05$. The data analysis was performed using GraphPad Prism 8.0 software for Mac OS X (GraphPad Software, San Diego CA).

\section{RESULTS}

Normality test showed the data was normally distributed. Therefore, a parametric test was used for statistical analysis. Among the 125 participants included in the study, $41.6 \%(n=52)$ were men and $58.4 \%(n=73)$ were women, with a mean age of the overall group of 7.34 years $(\mathrm{SD}= \pm 1.81)$. The ceft index ranged from 0 to $10 \mathrm{o}$ more, with a mean of $3.304(\mathrm{SD}= \pm 1.557)$. Dentition stage assessment of the study group showed that $8.8 \%$ presented temporary dentition, $16.8 \%$ mixed I stage, $63.2 \%$ mixed II stage and $11.2 \%$ presented permanent dentition. The distribution of the individuals was $72.80 \%(\mathrm{n}=91)$ for ECC group and $27.20 \%(n=34)$ for CC group. Mean cleft index for ECC and CC groups was $3.516( \pm 1.551)$ and $2.735( \pm$ 1.442 ), respectively, with statistically significant differences being observed $(p=0.0119)$. Descriptive data for both groups are shown in Table I. Individual genotype distributions assuming a recessive model are shown in Table II. No statistically significant differences were detected when comparing genotypic frequencies among the three gene variants, polymorphisms rs36094464 of DSPP gene $(p=0.276)$, rs566712 of RUNX2 gene $(p=0.288)$ and rs 198968 of KLK4 gene $(p=0.111)$. The same occurred when a recessive model was assumed $(p=0.371,0.617$ and 0.069 , respectively).

Fisher's exact test. The Table III shows the obtained ceft index across the studied genotypes in both groups. In the case of rs36094464 polymorphism of DSPP gene, individuals carrying the mutated $\mathrm{T} / \mathrm{T}$ genotype presented a higher mean ceft index $(p=0.033)$, and the same was observed when assuming a recessive model comparing wild type and heterozygous genotypes (A/AA/T) with the mutated genotype $(\mathrm{T} / \mathrm{T} ; p=0.022)$. These differences were confirmed by the analysis assuming a recessive model for the ECC group ( $p=0.025)$. Likewise, a higher mean ceft index was observed for the individuals carrying the mutated T/T genotype of the rs566712 variant in the RUNX2 gene ( $p=$ $0.025)$. The same was evidenced when assuming a recessive model through comparison of wild type and heterozygous genotypes $(\mathrm{G} / \mathrm{GG} / \mathrm{T})$ with the mutated genotype (T/T; $\mathrm{p}=0.012$ ). These differences were also confirmed by the $\mathrm{T} /$ $\mathrm{T}$ genotype analysis for ECC $(p=0.010)$ and for the recessive model in this group $(\mathrm{p}=0.002)$. Conversely, in the case of rs198968 polymorphism of KLK4 gene, no statistically significant differences were observed when comparing the different genotypes $(p=0.604)$ nor when assuming the recessive model $(p=0.906)$.

Table I. Description of the study sample $(n=125)$.

\begin{tabular}{|c|c|c|c|}
\hline Groups (n) & $\begin{array}{l}\text { Age } \\
(\text { mean } \pm \text { SD })\end{array}$ & $\begin{array}{l}\text { ceft index } \\
(\text { mean } \pm S D)\end{array}$ & $\begin{array}{l}\text { Dentition stage } \\
(\%, \mathrm{n})\end{array}$ \\
\hline \multirow[t]{2}{*}{ ECC (91) } & $6.538( \pm 1.393)$ & $3.516( \pm 1.552)$ & $\begin{array}{l}\text { Primary dentition: } 12.09 \text { (11) } \\
\text { Mixed I: } 23.08 \text { (21) }\end{array}$ \\
\hline & & & $\begin{array}{l}\text { Mixed II: } 60.44(55) \\
\text { Permanent: } 4.40(4)\end{array}$ \\
\hline CC (34) & $9.500( \pm 0.663)$ & $2.735( \pm 1.442)$ & $\begin{array}{l}\text { Temporal: } 0(0) \\
\text { Mixed I: } 0(0) \\
\text { Mixed II: } 70.59(24) \\
\text { Permanent } 2941(10)\end{array}$ \\
\hline$p$-value & $<0.0001 *$ & $0.0119 * *$ & $\begin{array}{l}\text { Permanent: } 29.41(10) \\
<0.0001 *\end{array}$ \\
\hline
\end{tabular}


SANHUEZA, J.; BUSTOS, L.; RODRÍGUEZ, N.; BORIE-ECHEVERRIA, E. \& SALINAS, P. Polymorphisms in DSSP (rs36094464) and RUNX2 (rs566712) genes contribute to the susceptibility of dental caries in childhood. Int. J. Morphol., 39(3):802-808, 2021

Table II. Frequency (\%) and genotype distribution of the studied variants assuming a recessive model in ECC ( $\mathrm{n}=91)$ and CC ( $\mathrm{n}=34)$ groups.

\begin{tabular}{|c|c|c|c|c|c|}
\hline & & $\mathrm{ECC}(\mathrm{n})$ & $\mathrm{CC}(\mathrm{n})$ & Total & $p$-value \\
\hline \multirow{5}{*}{ DSPP rs36094464 } & $A / A$ & $26.37(24)$ & $41.18(14)$ & $30.40(38)$ & \multirow{3}{*}{0.276} \\
\hline & $A / T$ & $43.96(40)$ & $38.24(13)$ & $42.40(53)$ & \\
\hline & $T / T$ & $29.67(27)$ & $20.59(7)$ & $27.20(34)$ & \\
\hline & $A A / A T$ & $70.33(64)$ & $79.41(27)$ & $72.80(91)$ & \multirow{2}{*}{0.371} \\
\hline & $T T$ & $29.67(27)$ & $20.59(7)$ & $27.20(34)$ & \\
\hline \multirow{5}{*}{ RUNX2 rs566712 } & $G / G$ & $39.56(36)$ & $50.0(17)$ & $42.40(53)$ & \multirow{3}{*}{0.288} \\
\hline & $G / T$ & $41.76(38)$ & $26.47(9)$ & $37.6(47)$ & \\
\hline & $T / T$ & $18.68(17)$ & $23.53(8)$ & $20.0(25)$ & \\
\hline & $G G / G T$ & $81.32(74)$ & $76.47(26)$ & $80.00(100)$ & \multirow{5}{*}{0.111} \\
\hline & $T T$ & $18.68(17)$ & $23.53(8)$ & $20.00(25)$ & \\
\hline \multirow{5}{*}{$\begin{array}{l}\text { KLK4 } \\
\text { rs198968 }\end{array}$} & $A / A$ & $29.67(27)$ & $26.47(9)$ & $28.8(36)$ & \\
\hline & $A / G$ & $30.77(28)$ & $14.71(5)$ & $26.4(33)$ & \\
\hline & $G / G$ & $39.56(36)$ & $58.82(20)$ & $44.8(56)$ & \\
\hline & $A A / A G$ & $60.44(55)$ & $41.18(14)$ & $55.20(69)$ & \multirow{2}{*}{0.069} \\
\hline & $G G$ & $39.56(36)$ & $58.82(20)$ & $44.80(56)$ & \\
\hline
\end{tabular}

Table III. Mean ceft index across genotypes of the studied polymorphisms in ECC ( $n=91)$ and CC ( $n=34)$ groups.

\begin{tabular}{|c|c|c|c|c|c|c|c|c|}
\hline \multirow{2}{*}{ Gene/polymorphism } & & \multicolumn{4}{|c|}{ Genotypes } & \multicolumn{3}{|c|}{ Alleles } \\
\hline & & $\mathrm{A} / \mathrm{A}$ & $\mathrm{A} / \mathrm{T}$ & $\mathrm{T} / \mathrm{T}$ & $p$-value & $\mathrm{A} / \mathrm{A}-\mathrm{A} / \mathrm{T}$ & $\mathrm{T} / \mathrm{T}$ & $p$-value \\
\hline \multirow{3}{*}{$\begin{array}{c}\text { DSPP } \\
\text { rs36094464 }\end{array}$} & $\mathrm{ECC}$ & $\begin{array}{c}3.042^{\mathrm{a}} \\
(1.654)\end{array}$ & $\begin{array}{l}3.425^{\mathrm{b}} \\
(1.615)\end{array}$ & $\begin{array}{l}4.074 \mathrm{c} \\
(1.207)\end{array}$ & 0.051 & $3.281(1.628)$ & $\begin{array}{c}4.074 \\
(1.207)\end{array}$ & 0.025 \\
\hline & $\mathrm{CC}$ & $\begin{array}{c}2.571^{\mathrm{a}} \\
(1.555)\end{array}$ & $\begin{array}{c}2.546^{\mathrm{b}} \\
(1.345)\end{array}$ & $\begin{array}{c}2.857 \mathrm{c} \\
(1.574)\end{array}$ & 0.865 & $2.704(1.436)$ & $\begin{array}{c}2857 \\
(1.574)\end{array}$ & 0.806 \\
\hline & Total & $\begin{array}{c}2.868^{\mathrm{a}} \\
(1.614)\end{array}$ & $\begin{array}{c}3.283^{\mathrm{b}} \\
(1.561)\end{array}$ & $\begin{array}{l}3.824^{\mathrm{ac}} \\
(1.359)\end{array}$ & 0.033 & 3.109 (1.587) & $\begin{array}{c}3.823 \\
(1.358)\end{array}$ & 0.022 \\
\hline \multirow{3}{*}{$\begin{array}{l}\text { RUNX2 } \\
\text { rs566712 }\end{array}$} & $\mathrm{ECC}$ & $\begin{array}{c}\mathrm{G} / \mathrm{G} \\
3.278^{\mathrm{a}} \\
(1.579)\end{array}$ & $\begin{array}{c}\mathrm{G} / \mathrm{T} \\
3.289^{\mathrm{b}} \\
(1.558)\end{array}$ & $\begin{array}{c}\mathrm{T} / \mathrm{T} \\
4.529 \mathrm{a}^{\mathrm{bc}} \\
(1.068)\end{array}$ & $p$-value & $3.283(1.557)$ & $\begin{array}{c}\mathrm{T} / \mathrm{T} \\
4.529 \\
(1.068)\end{array}$ & $p$-value \\
\hline & $\mathrm{CC}$ & $\begin{array}{l}2.353^{\mathrm{a}} \\
(1.367)\end{array}$ & $\begin{array}{c}3.333^{\mathrm{b}} \\
(1.5)\end{array}$ & $\begin{array}{c}2.875 \mathrm{c} \\
(1.458)\end{array}$ & 0.251 & $2.692(1.463)$ & $\begin{array}{c}2.875 \\
(1.458)\end{array}$ & 0.759 \\
\hline & Total & $\begin{array}{l}2.981^{\mathrm{a}} \\
(1.563)\end{array}$ & $\begin{array}{c}3.298^{\mathrm{b}} \\
(1.531)\end{array}$ & $\begin{array}{c}4^{\mathrm{ac}} \\
(1.414)\end{array}$ & 0.025 & $3.130(1.548)$ & $\begin{array}{c}4.000 \\
(1.414)\end{array}$ & 0.012 \\
\hline \multirow{4}{*}{$\begin{array}{c}\text { KLK4 } \\
\text { rs } 198968\end{array}$} & & $\mathrm{~A} / \mathrm{A}$ & $\mathrm{A} / \mathrm{G}$ & $\mathrm{G} / \mathrm{G}$ & $p$-value & $\mathrm{A} / \mathrm{A}-\mathrm{A} / \mathrm{G}$ & $\mathrm{G} / \mathrm{G}$ & $p$-value \\
\hline & ECC & $\begin{array}{r}3.296^{\mathrm{a}} \\
(1.613)\end{array}$ & $\begin{array}{c}3.607^{\mathrm{b}} \\
(1.397)\end{array}$ & $\begin{array}{l}3.611 \mathrm{c} \\
(1.644)\end{array}$ & 0.6842 & $3.455(1.501)$ & $\begin{array}{c}3.611 \\
(1.644)\end{array}$ & 0.641 \\
\hline & $\mathrm{CC}$ & $\begin{array}{l}2.667^{\mathrm{a}} \\
(1.323)\end{array}$ & $3 \mathrm{~b}(1.225)$ & $\begin{array}{c}2.7^{\mathrm{c}} \\
(1.523)\end{array}$ & 0.9297 & $2.786(1.251)$ & $\begin{array}{c}2.700 \\
(1.593)\end{array}$ & 0.868 \\
\hline & Total & $\begin{array}{c}3.139^{a} \\
(1.552)\end{array}$ & $\begin{array}{c}3.515^{\mathrm{b}} \\
(1.372)\end{array}$ & $\begin{array}{c}3.286 \mathrm{c} \\
(1.670)\end{array}$ & 0.6042 & $3.319(1.470)$ & $\begin{array}{c}3286 \\
(1.670)\end{array}$ & 0.906 \\
\hline
\end{tabular}

* Similar letters indicate significant statistical differences.

ANOVA test and multiple comparisons by Scheffé's method. To estimate the ceft index associated with the variables under study, we used a multiple regression model adjusted by age groups and the T/T genotype of the rs36094464 polymorphism. Since the sex variable was not associated with ceft index it was excluded from the model. Thus, the ECC group and the presence of the $\mathrm{T} / \mathrm{T}$ genotype explained the mean ceft index by $9 \%(p=0.004)$. Moreover, significant differences were observed when assuming the recessive model (T/T versus A/A-A/T), adjusting for ECC and CC groups. An increased in 0.65 units of mean ceft index was observed in children of the ECC group with T/T genotype ( $p=0.03$ ). Similarly, when comparing between groups and adjusting for genotype, mean ceft index increased by 0.72 units in the ECC group $(p=0.012)$, observing significant differences. Confidence intervals of marginal estimates proved no significant differences for ceft index, nor between age groups, the studied genotypes or among genotypes in each of the age groups. The final model is expressed as follows: ceft $=2.602+0.648 * \mathrm{~T} / \mathrm{T}$ genotype + $0.722 *$ ECC. For the regression model of the rs566712 polymorphism of RUNX2 gene, age and ceft index were included while sex variable was excluded of the final 
regression model. It was observed that ECC group and T/T genotype explained mean ceft index by $11 \%(p=0.001)$. Furthermore, significant mean ceft index differences were observed among T/T vs G/G-G/T genotypes, assuming a recessive model and adjusting by age groups, increasing the average ceft index by 0.92 units in children carrying the T/T genotype $(p=0.007)$. When comparing between age groups, adjusting for the mutated genotype, the differences were statistically significant with mean ceft index increasing by 0.83 units in the ECC group presenting the T/T genotype $(p=0.007)$. Confidence intervals of the marginal estimates indicated that there are no significant differences in ceft index between age groups, nor for each of the alleles or between the alleles in each of the age groups. The constant of this model was 2.519. In the case of polymorphism rs 198968 of the KLK4 gene, sex variable was also excluded from the final regression model, as there was no association. The $\mathrm{G} / \mathrm{G}$ genotype and age groups explain $4 \%$ the average ceft index $(p=0.04)$. However, no significant differences were observed in mean ceft index between $\mathrm{G} / \mathrm{G}$ vs $\mathrm{A} / \mathrm{A}-\mathrm{A} / \mathrm{G}$ genotypes, assuming a recessive model and adjusting by age groups $(p=0.74)$. When comparing between age groups, and adjusting for $\mathrm{G} / \mathrm{G}$ genotype, the differences were significant with a mean ceft index increasing by 0.80 units in the ECC group presenting the $\mathrm{G} / \mathrm{G}$ genotype $(p=0.01)$. Confidence intervals of the marginal estimates indicated that there were no significant differences in ceft index between age groups, nor in each of the alleles or between the alleles in each of the age groups.

\section{DISCUSSION}

In recent years, several studies have focused on the analysis of genes involved in the normal development of the tooth and its relation with dental caries (Abbasog $` l u ~ e t ~ a l$. , 2015; Piekoszewska-Zietek et al.). In this context, it is difficult to establish that one or several genes are associated with dental caries, but it is important to achieve progress in the matter and contribute to the current evidence of this multifactorial disease. Notably, the role of genetic factors in the genesis of dental caries, in both primary and permanent dentition, has been reported. However, the degree to which genes contribute to the development of dental caries and whether these genes differ between primary and permanent conditions is largely unknown (Piekoszewska-Zietek et al.).

It is important to realize that enamel is the most highly mineralized tissue in the human body and the amelogenesis phase is under strict genetic control. Moreover, its size, shape, structure and composition are affected by genetic variations, so studies on the genetic association of dental caries have suggested that variations in genes involved in enamel formation could influence the susceptibility to this pathology, which starts with demineralization (Pang et al., 2017). Using an in vitro $\mathrm{pH}$ cycle model, a previous study showed that genetic variations in enamel formation genes are associated with changes in enamel microhardness (Shimizu et al., 2013). This evidence helps to get a better understanding of the results obtained in this work.

In the analyzed group, the mean ceft index for the ECC group was higher than for the $\mathrm{CC}$ group. This finding differs from reports that indicate that ceft index increases according to the individual's age. When comparing our evidence with Chilean children population records, the mean ceft index observed in our study group is lower than that reported by MINSAL in studies conducted in 6 to 8 -year-old children (Fuentes et al., 2014; mean ceft index $=4.32$ ). In this context, it should be clarified that the study population corresponds to children who receive attention on a regular basis and belong to a medium socioeconomic stratum, which could explain these differences (Shiboski et al., 2003), since in other studies a higher prevalence of caries in low-income groups was found. The latter possibly due to the influence of dietary patterns, low self-care levels, low demand for preventive care, worse oral hygiene habits and difficulties in accessing dental services (Nunes \& Perosa, 2017). There was no association between caries and sex, results that are in agreement with those described by Pang et al., who reported that there is no association between sex and enamel properties or demineralization.

For the rs36094464 polymorphism of the DSPP gene, a higher mean ceft index was observed in individuals carrying the mutated $\mathrm{T} / \mathrm{T}$ genotype. The latter was also true when assuming the recessive model comparing the wild type and heterozygous genotype (A/AA/T) with the mutated T/T genotype. These differences were confirmed when assuming the recessive model for the ECC group. This polymorphism (c.202A1T) in exon 4 which leads to a single amino acid change (p.R68W) was previously reported in a Swedish family as a mutation causing DI type II (Malmgren et al., 2004). These authors reported initial functional studies suggesting that the mutated DSPP remained in the odontoblasts endoplasmic reticulum. This alteration has been reported (Holappa et al., 2006) as a polymorphism that occurred in $15 \%$ of the control population in a study conducted in Finland. Moreover, allelic frequencies of $6 \%$ and $16 \%$ were reported for this SNP in Caucasian and African American control populations, respectively.

A genotypic frequency of $13.6 \%$ for the T/T genotype in European populations has been previously reported (Hart \& Hart, 2007). In the present study, we have reported a genotypic frequency of $27.2 \%$. Taken together, these findings 
and the data presented in this study suggest that this variant is a polymorphism and not a mutation associated with the pathogenesis of DI type II, since none of the individuals in the sample showed signs of the disease. It is important to note that DSPP is a gene that encodes a 940 amino acid parenteral polypeptide which is cleaved into two crucial proteins for dentinogenesis, dentine sialoprotein and dentine phosphoprotein. Consequently, mutations in this gene are associated with dentine disease pathogenesis.

For the rs566712 polymorphism of the RUNX2 gene, a greater mean ceft index is observed for the individuals carrying the mutated T/T genotype, the same when assuming a recessive model comparing the wild type and heterozygous genotypes (G/GG/T) with the mutated genotype. These differences were also observed when the T/T genotype analysis was carried out for ECC and for the recessive model in this group. The expression of this gene is pivotal in the differentiation process of osteoblasts, also inhibiting the differentiation of adipocytes, a process that seems to be key for the tooth histo-differentiation (Komori, 2018). This transcription factor has been identified as responsible for the occurrence of supernumerary teeth. Moreover, its relation to craniofacial dysplasia has been acknowledged. Mutations associated with these alterations have been already identified, being an important object of study in the process of tooth formation. It should be noted that there is a lack of evidence on the association of polymorphisms of this gene and caries history in children, with this work being the first to associate the presence of a variant in this gene with a history of caries in early childhood.

The KLK4 gene is expressed later during the transition through the maturation stages as the enamel hardens. The main functions of matrix metallopeptidase 20 (MMP-20) and KLK4 in tooth enamel formation are to facilitate an organized replacement of the organic matrix by the mineral, generating an enamel layer. No differences were observed among the genotypes or when assuming the recessive model when assessing the presence of the rs 198968 polymorphism of KLK4 gene. Previously, the $\mathrm{A} / \mathrm{G}$ and $\mathrm{G} / \mathrm{G}$ genotypes of this polymorphism were reported as protective in ECC. Nevertheless, taking into account that dental caries is the result of a chronic imbalance between multiple risk and protective factors and that recent studies continue to demonstrate that genetic variation in the host is associated with this disease, these variations may be playing a role in the etiology of ECC as risk or protective factors (Abbasoglu et al.). In the present study, we have shown that the carriers of GG genotype had a higher mean ceft index compared to individuals who did not carry it; however, these differences did not reach significance. This trend is coincident with results reported previously (Kamel et al.) who associated the presence of the $\mathrm{G} / \mathrm{G}$ genotype to the dental caries phenotype.
The genetic variability observed in amelogenesis would contribute to the appearance of structural alterations of the enamel and could cause higher levels of loss of minerals in acidic conditions and / or facilitate bacterial binding and deposit of biofilms. Nevertheless, it should be noticed that the evidence on these genetic associations has been controversial, being necessary at this point to advance towards functional studies of these polymorphisms in order to verify their real contribution to this problem. Evidence from this and other studies confirm the role of genes involved in enamel formation on caries susceptibility in humans.

A limitation of our study is that dental caries disease stands out for its multifactorial etiology, such as socioeconomic, ethnic and cultural factors. Furthermore, although there is evidence of genetic susceptibility to dental caries, it is logical that there is also protection associated with genes. Both situations were not considered in the study. Furthermore, it is important to note that the results obtained in our study may or may not be generalizable to other populations. Our results are limited to the specific populations that participated in the study. Therefore, the reproducibility of the study in other ethnic groups will improve the generalizability of the results obtained in this study.

Finally, we believe this study is important for pediatric dentistry because it highlights the role of DSSP (rs36094464) and RUNX2 (rs566712) towards susceptibility to dental caries during early childhood, genetic evaluation is useful for the prediction and prevention of dental caries in early childhood. In addition, because it provides evidence that indicates that genetic factors are implicated in the etiology of caries. In conclusions the studied polymorphisms on DSSP and RUNX2 genes are associated with dental caries disease susceptibility in early childhood. This susceptibility could have morphological consequences on tooth microarchitecture, favoring the appearance of microlesions. Also, no association was found for the studied polymorphism of the KLK4 gene with dental caries disease susceptibility in early childhood. Taking into account that more research is necessary to assess the functional role of these polymorphisms and the changes induced by them on tooth microarchitecture, the results of this work are a contribution to the search for relevant biological markers of dental caries in early childhood.

\section{ACKNOWLEDGMENTS.}

The authors would like to thank the dentists at the Dental Clinic of the Universidad Mayor and the patients and their families who generously agreed to participate in this research. This research was co-financed by Thesis Support Program of School of Dentistry, Universidad Mayor and DI-PUCV 039.472/ 2020 Pontificia Universidad Católica de Valparaíso, Chile. 
SANHUEZA, J.; BUSTOS, L.; RODRÍGUEZ, N.; BORIEECHEVERRIA, E. \& SALINAS, P. Los polimorfismos en los genes DSSP (rs36094464) y RUNX2 (rs566712) contribuyen a la susceptibilidad de la caries dental en la infancia. Int. J. Morphol., 39(3):802$808,2021$.

RESUMEN: La caries dental corresponde a una enfermedad crónica, no contagiosa, dinámica y de origen multifactorial. Actualmente existe evidencia de cómo los factores genéticos podrían incluirse como agentes predisponentes, sin embargo, esta evidencia es diversa e incipiente. Se realizó un estudio transversal para investigar las posibles asociaciones entre los polimorfismos DSPP (rs36094464), RUNX2 (rs566712) y KLK4 (rs198968) y la caries en la infancia. Se colectaron muestras de saliva de niños (de 2 a 11 años de edad) y se genotipificaron para los polimorfismos DSPP (rs36094464), RUNX2 (rs566712) y KLK4 (rs198968). Mediante el índice ceft se determinó su historial de caries y se estudiaron las variantes genéticas mediante técnicas de biología molecular. Los datos obtenidos indican que los polimorfismos del DSSP (rs36094464) y RUNX2 (rs566712) están asociados y contribuyen a la susceptibilidad de la enfermedad de caries dental en la infancia, ya que están además - relacionados con el historial de caries. En conclusión, los polimorfismos estudiados en los genes DSSP y RUNX2 se asocian a la aparición de microlesiones que contribuirían a la susceptibilidad a la enfermedad de caries dental en la infancia. Creemos que este estudio es importante para la odontopediatría porque destaca el papel de DSSP (rs36094464) y RUNX2 (rs566712) y la susceptibilidad a la caries dental durante la infancia, además resalta la utilidad de la evaluación genética para la predicción y prevención de la caries dental y porque aporta evidencia que indica que los factores genéticos están implicados en la etiología de la caries

\section{DSPP; RUNX2.}

PALABRAS CLAVE: Caries; Infancia; Polimorpfismos;

\section{REFERENCES}

Abbasoglu, Z.; Tanboga I' ; Küchler E, Deeley, K.; Weber, M.; Kaspar, C.; Korachi, M. \& Vieira, A. Early childhood caries is associated with genetic variants in enamel formation and immune response genes. Caries Res., 49(1):70-7, 2015

Anil, A. \& Anand, P. Early childhood caries: prevalence, risk factors, and prevention. Front. Pediatr., 5:157, 2017.

Bretz, W. A.; Corby, P.; Schork, N. \& Hart, T. C. Evidence of a contribution of genetic factors to dental caries risk. J. Evid. Based Dent. Pract., 3(4):185-9, 2003.

Colombo, N. H.; Kreling, P. F.; Ribas, L. F. F.; Pereira, J. A.; Kressirer, C. A.; Klein, M. I.; Tanner, A. C. R. \& Duque, C. Quantitative assessment of salivary oral bacteria according to the severity of dental caries in childhood. Arch. Oral Biol., 83:282-8, 2017.

Fuentes, N. J.; Corsini, M. G.; Bornhardt, T.; Ponce, V. A. \& Ruiz, F. Á. Prevalence of dental caries and oral hygiene level in children aged 6 years attended under GES and JUNAEB models. Int. J. Odontostomat., 8(3):385-91, 2014.

Hart, P. S. \& Hart, T. C. Disorders of human dentin. Cells Tissues Organs, 186(1):70-7, 2007.

Holappa, H.; Nieminen, P.; Tolva, L.; Lukinmaa, P. L. \& Alaluusua, S. Splicing site mutations in dentin sialophosphoprotein causing dentinogenesis imperfecta type II. Eur. J. Oral Sci., 114(5):381-4, 2006.

Kamel, R.; Refaey, S.; Abu El-Sood, H. \& Mohsen, A. Prevalence and risk factors for early childhood caries in children less than 6 years old: a systematic review. IPROC, 4(1):e10564, 2018.
Komori, T. Runx2, an inducer of osteoblast and chondrocyte differentiation. Histochem. Cell Biol., 149(4):313-23, 2018.

Lu, Y.; Papagerakis, P.; Yamakoshi, Y.; Hu, J. C.; Bartlett, J. D. \& Simmer, J. P. Functions of KLK4 and MMP-20 in Dental Enamel Formation. Biol. Chem., 389(6):695-700, 2008

Maciejewska, I. \& Chomik, E. Hereditary dentine diseases resulting from mutations in DSPP gene. J. Dent., 40(7):542-8, 2012.

Malmgren, B.; Lindskog, S.; Elgadi, A. \& Norgren, S. Clinical, histopathologic, and genetic investigation in two large families with dentinogenesis imperfecta type II. Hum. Genet., 114(5):491-8, 2004.

Nunes, V. H. \& Perosa, G. B. Dental decay in 5-year-old children: sociodemographic factors, monitoring points and parental attitudes. Cien. Saude Colet., 22(1):191-200, 2017.

Opal, S.; Garg, S.; Jain, J. \& Walia, I. Genetic factors affecting dental caries risk. Aust. Dent. J., 60(1):2-11, 2015.

Ozdemir, D.; Hart, P. S.; Ryu, O. H.; Choi, S. J.; Ozdemir-Karatas, M.; Firatli, E.; Piesco, N. \& Hart, T. C. MMP20 active-site mutation in hypomaturation amelogenesis imperfecta. J. Dent. Res., 84(11):1031-5, 2005.

Pang, L.; Zhi, Q.; Zhuang, P.; Yu, L.; Tao, Y. \& Lin, H. Variation in enamel formation genes influences enamel demineralization in vitro in a Streptococcus mutans biofilm model. Front. Physiol., 8:851, 2017.

Perinpanayagam, H.; Martin, T.; Mithal, V.; Dahman, M.; Marzec, N.; Lampasso, J. \& Dziak, R. Alveolar bone osteoblast differentiation and Runx2/Cbfa1 expression. Arch. Oral Biol., 51(5):406-15, 2006.

Peter, S. Essential of Preventive and Community Dentistry. 3rd ed. New Delhi, Arya Publishing House, 2006. pp.148-9.

Philip, N.; Suneja, B. \& Walsh, L. J. Ecological approaches to dental caries prevention: paradigm shift or shibboleth? Caries Res., 52(1-2):153-65, 2018.

Piekoszewska-Zie ‘tek, P.; Turska-Szybka, A. \& Olczak-Kowalczyk, D. Single nucleotide polymorphism in the aetiology of caries: systematic literature review. Caries Res., 51(4):425-4, 2017.

Shaffer, J. R.; Wang, X.; Feingold, E.; Lee, M.; Begum, F.; Weeks, D. E.; Cuenco, K. T.; Barmada, M. M.; Wendell, S. K.; Crosslin, D. R.; et al. Genomewide association scan for childhood caries implicates novel genes. J. Dent. Res., 90(12):1457-62, 2011.

Shiboski, C. H.; Gansky, S. A.; Ramos-Gomez F.; Ngo, L.; Isman, R. \& Pollick, H. F. The association of early childhood caries and race/ethnicity among California preschool children. J. Public Health Dent., 63(1):38-46, 2003.

Shimizu, T.; Deeley, K.; Briseño-Ruiz, J.; Faraco Jr., I. M.; Poletta, F. A.; Brancher, J. A.; Pecharki, G. D.; Küchler, E. C.; Tannure, P. N.; Lips, A.; et al. Finemapping of 5q12.1-13.3 unveils new genetic contributors to caries. Caries Res., 47(4):273-83, 2013

Shimizu, T.; Ho, B.; Deeley, K.; Briseño-Ruiz, J.; Faraco Jr., I. M.; Schupack, B. I.; Brancher, J. A.; Pecharki, G. D.; Küchler, E. C.; Tannure, P. N.; et al. Enamel formation genes influence enamel microhardness before and after cariogenic challenge. PLoS One, 7(9):e45022, 2012.

Vieira, A. R.; Modesto, A. \&Marazita, M. L. Caries: review of human genetics research. Caries Res., 48(5):491-506, 2014.

Wang, X.; Willing, M. C.; Marazita, M. L.; Wendell, S.; Warren, J. J.; Broffitt, B.; Smith, B.; Busch, T.; Lidral, A. C. \& Levy, S. M. Genetic and environmental factors associated with dental caries in children: the Iowa Fluoride Study. Caries Res., 46(3):177-84, 2012.

World Health Organization. Oral Health. Geneva, World Health Organization, 2019.

\section{Corresponding author: \\ Paulo Salinas \\ Institute of Biology \\ Pontificia Universidad Católica de Valparaíso \\ Valparaíso \\ CHILE}

E-mail: paulo.salinas@pucv.cl

Received: 20-01-2021

Accepted: $21-02-2021$ 